\title{
ОБ ОДНОМ ПОДХОДЕ К КАТЕГОРИЗАЦИИ ЛЕКСИЧЕСКОЙ АСПЕКТУАЛЬНОСТИ В РУССКОМ ЯЗЫКЕ
}

\author{
A PROPOSAL FOR THE CATEGORIZATION \\ OF LEXICAL ASPECTUALITY IN RUSSIAN
}

\author{
VLADIMIR KLIMONOV
}

\begin{abstract}
The paper deals with the categorization of verbal situations (lexical aspects: events, processes, and states) and their subcategorization according to finer Aktionsart distinctions. The proposed two-component model for the categorization of lexical aspectuality is based on uniform quantitative features. Four subclasses of events will be distinguished, which will be subclassified further.

Vladimir Klimonov, Humboldt Universität Berlin, Berlin - Niemcy, klimonov@web.de
\end{abstract}

\section{1.Двухкомпонентная модель категоризации лексической аспектуальности}

В аспектологии принято различать грамматическую аспектуальность (ГА) и лексическую аспектуальность (ЛА). Ю. С. Маслов ${ }^{1}$ отделяет вид как грамматическую категорию от аспектуальных классов (AK), имеющих двоякий, лексико-грамматический характер. Под ГА понимается в настоящей работе система видовых парадигм полных, выражаемых противопоставлением форм совершенного вида (СВ) и несовершенного вида (НСВ), и дефективных, выражаемых формами только одного вида (СВ или НСВ). Так, приставка на- у глагола намокнуть (= стать мокрым), производного от глагола мокнуть (= становиться мокрым), не меняет лексического значения исходного глагола мокнуть. Противопоставление типа мокнуть - намокнуть (о рубахе) является поэтому чисто грамматическим противопоставлением форм НСВ и СВ, т. е. видовой парой (или видовой парадигмой). Зону ЛА составляют отглагольные дериваты с морфологическими маркерами (MМ), модифицирующими значение исходных глаголов. Приставка про- у глагола промокнуть, производного от того же самого глагола мокнуть, вносит

1 Ю. С. М а с л о в, Об основных понятиях аспектологии, [в:] его же, Очерки по аспектомогии, Ленинград 1984, с. 8-10. 
в значение исходного глагола мокнуть дополнительный смысл интенсивности глагольного действия: промокнуть (до костей/до нитки) (= стать совсем мокрым). Корреляция типа мокнуть - промокнуть (о рубахе), в которой соотносительные видовые формы НСВ и СВ не обнаруживают тождества своего лексического значения, представляет собой словообразовательную деривацию.

Анализ ЛА проводится в настоящей работе в рамках двухкомпонентной модели категоризации ЛА. Верхний ярус репрезентации ЛА образуют глобальные категории события (или эвентивы), процессы (или процессивы) и состояния (или стативы), представляющие собой номинации самых общих типов глагольных ситуаций и соответствующих им классов глаголов. Эти концептуальные категории, релевантные как для лингвистики, так и для философии, А. П. Д. Мурелатос ${ }^{2}$ называет „онтологической трихотомией”. Как по своему содержанию (обобщенный характер номинации), так и по своей форме (тернарная структура) эти категории обнаруживают аналогию с грамматическими видами в славянских языках, поэтому я называю их лексическими видами (ЛВ).

События (или эвентивы) типа прорисовать (картину с понедельника до четверга) определяются как ограниченные во времени целостные, т. е. однофазовые глагольные ситуации. Начальная и конечная границы действия включаются в события как их ингерентные характеристики. Считается, что у глаголов с недуративной семантикой (т. Н. моментативов) типа вскрикнуть обе границы действия сливаются в одной точке. Процессы (или процессивы) типа покашливать (= слегка, с перерывами кашлять) обозначают неограниченные во времени нецелостные, т. е. многофазовые, глагольные ситуации, рассматриваемые безотносительно к начальной и конечной границам действия. Состояния (или стативы) типа недолюбливать называют не развивающиеся во времени глагольные ситуации, не обнаруживающие внутреннего членения на фазы. Такие глагольные действия не имеют границ (начальной и конечной).

Нижний ярус репрезентации ЛА составляют специфические для каждого языка частные разновидности ЛВ, представленные в виде системы, т. е. упорядоченного множества способов действия (СД). Удельный вес глаголов со значением СД в словарном составе русского языка относительно небольшой. А. В. Исаченко ${ }^{3}$ указывает на то, что подавля-

2 A. P. D. M o u r e 1 a t o s, Events, Processes, and States, "Syntax and Semantics" 1981, no. 14, c. 199-201.

${ }^{3}$ A.V. I s a č e n k o, Die russische Sprache der Gegenwart, Teil I: Formenlehre, Halle (Saale) 1962, c. 387. 
ющее большинство глаголов в русском языке не обнаруживает значений СД. АК и конституирующие их СД А.В. Бондарко 4 причисляет к периферии аспектуальности. Предметом исследования является субкатегоризация и формальная манифестация класса глаголов (или глагольных лексем) со значением событий. В основу категоризации глаголов со значением событий на подклассы в настоящей работе положены квантитативные параметры глагольного действия, которые считаются конститутивными для модификации глагольного действия. Количественные характеристики глагольного действия не меняют значения действия как такового. Они только вносят в содержание исходного (производящего) глагола дополнительную семантическую информацию, касающуюся квантитативных параметров глагольного действия. Квантитативные значения рассматриваются в настоящей работе как координаты (или отметки), специфицированные (определенные, или абсолютные) и неспецифицированные (неопределенные, или относительные) на темпоральной шкале аспектуальности, квантифицирующей внутреннюю темпоральную структуру глагольного действия, и на нетемпоральной шкале аспектуальности, квантифицирующей глагольное содержание в целом, включая и его участников (актантов, или партиципантов).

Следует отметить, что в традиционном представлении глаголы с временными параметрами глагольного действия исключаются из сферы количественной аспектуальности (см., напр., монографию А. В. Исаченко ${ }^{5}$ и академическую грамматику русского языка 6 ). Не все лингвисты разделяют эту точку зрения. Так, в Русской Грамматике, изданной в Праге 7 у указывается, что фазисные СД, к которым причисляются и ограничительные СД, выражают ограничение глагольного действия во времени, т. е. квантификацию глагольного действия. Я. Ставницка 8 также относит т. н. временные группировки СД к количественной аспектуальности. Во временных СД ограничение глагольного действия

${ }^{4}$ А.В. Б о н д а р к о, Содержание и типы аспектуальных отнотений, [в:] Теория функииональной грамматики: Введение. Аспектуальность. Временная локализованность. Таксис, Ленинград 1987, с. 52.

5 A.V. I s a č е $\mathrm{n} \mathrm{k} \mathrm{o,} \mathrm{указ.} \mathrm{соч.,} \mathrm{с.} \mathrm{386-387.}$

6 Русская грамматика, ред. Н. Ю. Шведова, Наука, т. І, Москва 1980, с. 596-598.

7 Русская Грамматика, kn. 1, Academia, Československé akademie věd, Praha 1979, c. 244-245.

$8 \mathrm{~J}$. S t a w n i c k a, Parametry kwantyfikacyjne akcji werbalnej w języku polskim, [в:] B. B r e h m e r et al. (Hrsg.), Aspekte, Kategorien und Kontakte slavischer Sprachen, Festschrift für Volkmar Lehmann zum 65. Geburtstag, Hamburg 2008, c. 385. 
во времени неразрывно связано с лимитацией самого глагольного действия. Ограничение глагольного действия во времени, т. е. фокусирование определенного временного интервала глагольного действия, сопряжено с ограничением в полноте проявления глагольного действия, т. е. с выделением некоего кванта (некой доли или некой части) глагольного действия как такового. Так, напр., значение непродолжительного временного интервала у глаголов делимитативного СД (ср. почитать газету недолго / всего несколько минут) сочетается со значением малой (или небольшой) меры (или степени) интенсивности глагольного действия (ср. почитать немного газету). В зависимости от семантики глагола и от контекста перевес получает в отдельных случаях временная или невременная интерпретация значения глагола, ср. коротко посовещаться и немного погулять.

Наложение рассмотренных характеристик глагольного действия друг на друга (темпоральная и нетемпоральная шкалы, а также специфицированные и неспецифицированные отметки на этих шкалах) дает в итоге четыре подкласса глаголов, обозначающих события, со специфическими для каждого из них параметрами квантификации. Эти аспектуальные подклассы глаголов со значением событий субкатегоризируются далее на разряды (группы и подгруппы) СД в соответствии с дальнейшей дифференциацией квантитативных параметров, специфических для каждого из аспектуальных подклассов (см. раздел 2).

\section{2. Субкатегоризация класса глаголов со значением событий}

Первый и второй подклассы объединяют глагольные лексемы со значением временной квантификации глагольного действия. Субкатегоризация таких глагольных лексем на шкале внутренней темпоральности глагольного действия представлена на схеме 1.

Первый подкласс глагольных лексем со специфицированными отметками на шкале внутренней темпоральности ([+СПЕЦ]) обозначает фазовые (фазисные) характеристики глагольного действия. Этот подкласс подразделяется на две группы. К первой группе относятся глагольные лексемы, фокусируюшие некую долю (или часть) глагольного действия как начальную фазу действия [+НАЧ]. Такие глагольные лексемы образуют начинательные СД, а именно инхоативный СД типа заговорить и ингрессивный СД типа пойти. Глаголы инхоативного СД обозначают начальный отрезок ситуации, представленный глагольным действием, ср. заговорить (= начать говорить). У глаголов ингрессивного СД отсутствует четкая граница между началом действия и действием в целом, ср. пойти $b$ театр (= направиться в театр). Глагольное действие воспринимается здесь в единстве его начала и продолжения. 
Глагольные лексемы, относящиеся ко второй группе, фокусируют некий квант глагольного действия, обозначающий последнюю, завершающую часть глагольного действия [-НАЧ]. Сюда относятся эгрессивные глаголы комплетивного СД типа договорить и финитивного СД типа отговорить. Глаголы комплетивного СД выражают завершение конечной фазы глагольного действия, ср. договорить (= довести свою речь до конца). Глаголы финитивного СД обозначают прекращение глагольного действия, ср. отговорить (= кончить говорить). Срединная фаза действия в русском языке морфологически не выражается. Транскурсивное, или интратерминальное, значение передается глагольным словосочетанием типа продолжать / не переставать говорить...

Схема 1. Субкатегоризация событий с временной квантификацией глагольного действия

Сокращения: ВК = временная квантификация, СПЕЦ = спецификация, НАЧ = начало, ДОЛГ = долговременность

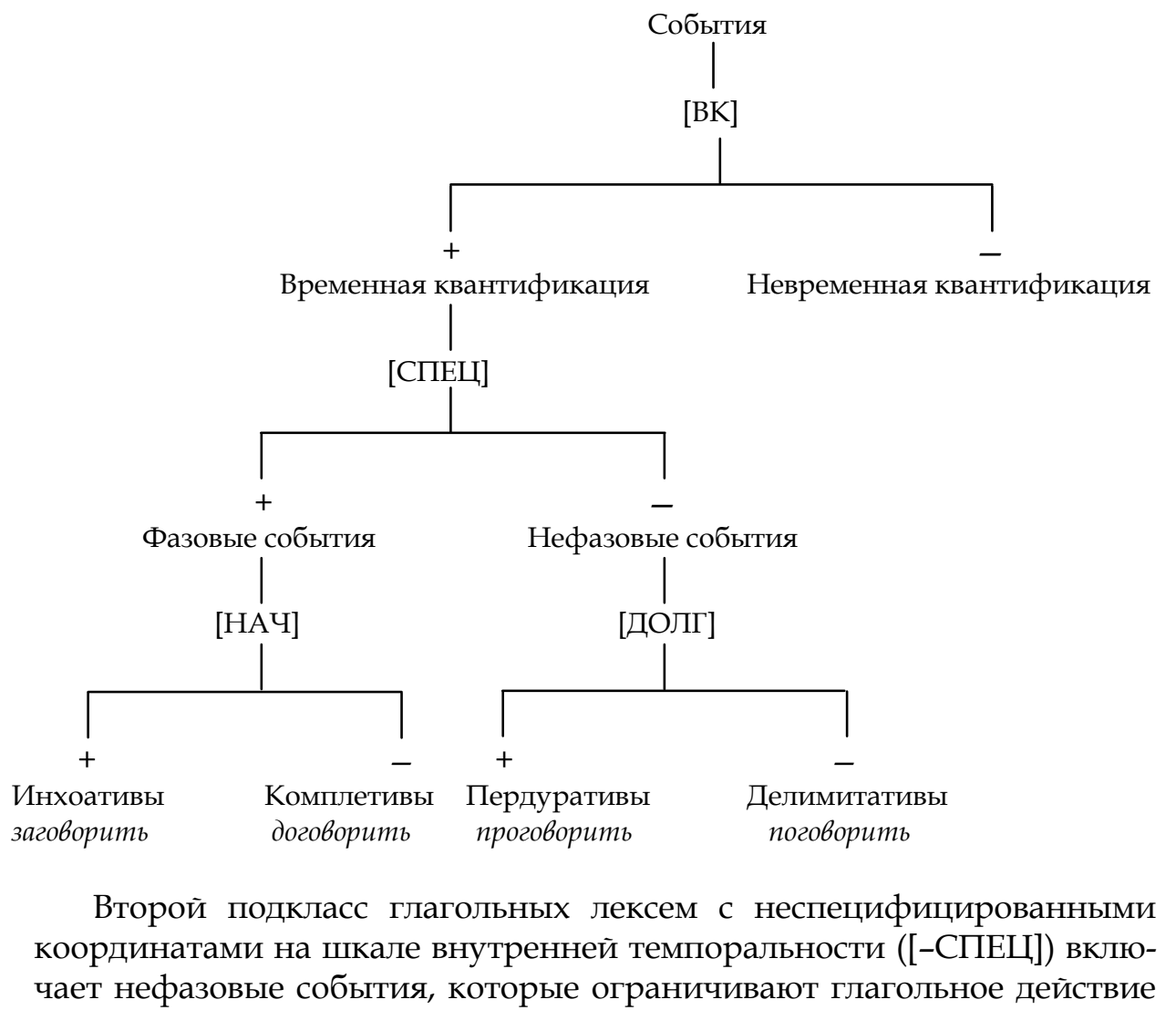


во времени и представляют его как относительно продолжительное, или долговременное (= глаголы длительно-ограничительного, или пердуративного, СД типа проговорить весь вечер), или как относительно непродолжительное, или недолговременное (= глаголы недлительно-ограничительного, или делимитативного СД типа поговорить всего несколько минут).

В состав третьего и четвертого подклассов входят глагольные лексемы со значением невременной квантификации глагольного действия (см. схему 2).

Схема 2. Субкатегоризация событий с невременной квантификацией глагольного действия

Сокращения: СЧЕТ = счетность, ЕДИН = единичность, ИНТ = интенсивность

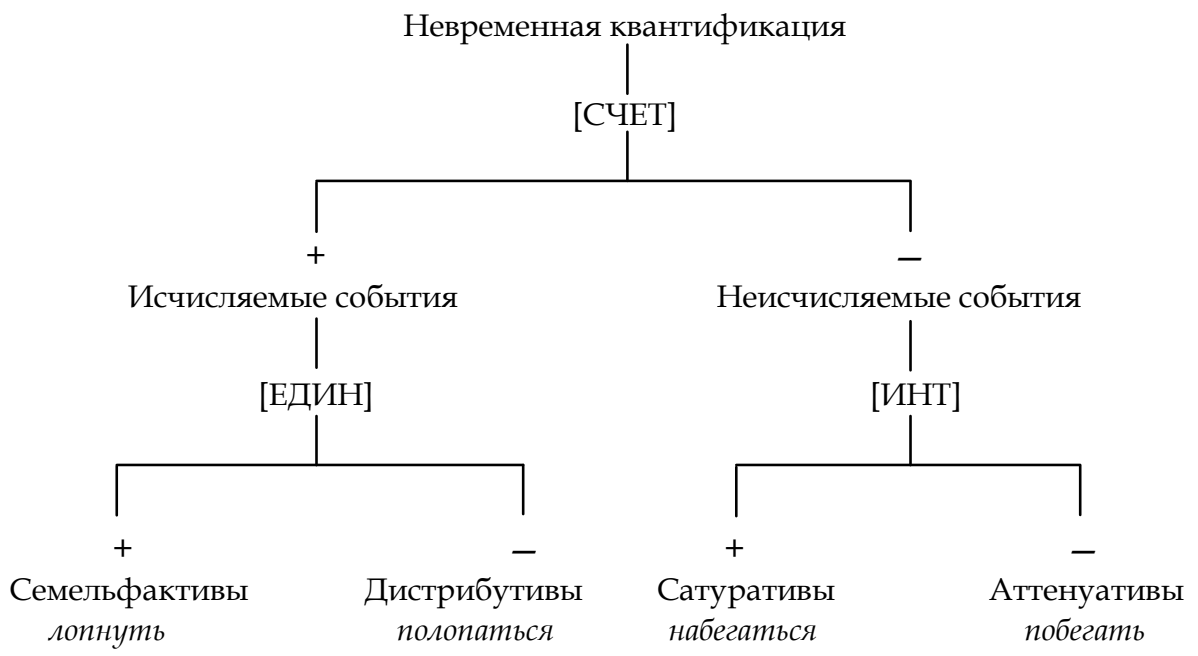

Третий подкласс глагольных лексем с признаком [+СЧЕТ] включает в себя исчисляемые, или нумеральные, события. Такие глагольные лексемы делятся на две группы. К первой из них относятся глагольные лексемы со значением однократных (разовых) действий (одноактного, или семельфактивного, действия с признаком [+ЕДИН] типа лопнуть (об оконном стекле)). Вторая группа включает глагольные лексемы со значением многократных действий с признаком [-ЕДИН], а именно со значением постепенного накопления объектов глагольного действия (т. н. кумулятивный СД типа накупить (множество книг)), а также глагольные лексемы со значением многократных распределительных действий, представляющих действие как поочередность отдельных его актов (т. н. дистрибутивные СД). Последние обнаруживают два подтипа, первый из которых представляет действие как поочередную по- 
следовательность актов, касающихся многих субъектов (т. н. субъектно-дистрибутивный СД типа полопаться (об оконных стеклах во время пожара)), а второй из них репрезентирует действие, направленное на множество его объектов (т. н. объектно-дистрибутивный СД типа перемыть (всю посуду)).

К четвертому подклассу относятся глаголы со значением неисчисляемых, или транснумеративных, событий с признаком нечисловой квантификациии глагольного действия [-СЧЕТ], т. е. градации глагольного действия по степени интенсивности. Этот подкласс составляют события со значением высокой степени интенсивности глагольного действия ([+ИНТ]) (группа 1) и события, обозначающие малую или ослабленную степень интенсивности глагольного действия ([-ИНТ]) (группа 2). Глаголы первой группы распадаются на две подгруппы. Первая из них включает в себя глаголы, указывающие на интенсивность действия субъекта. К этой подгруппе относятся глаголы, обозначающие полноту осуществления глагольного действия (сатуративный, или сативный, СД: набегаться (вдоволь)), исчерпанность действия (эксгаустативный, или эксгаустивный, СД: измучиться (= дойти до изнеможения)), доведение действия субъектом до излишества (чрезмерно-длительный СД: заговориться (= проговорить слишком долго)). Вторую подгруппу образуют глаголы со значением интенсивности действия по отношению к его объекту или объектам. Эта подгруппа включает глаголы, указывающие на то, что действие охватывает весь объект или множество объектов (тотальный СД: исписать (всю тетрадь)), или на то, что степень проявления действия выше принятого стандарта (чрезмерно-эффективный СД: заговорить (собеседника) (= утомить собеседника разговором)). Вторую группу четвертого подкласса составляют глаголы со значением малой или ослабленной степени интенсивности глагольного действия (смягчительный, или аттенуативный, СД). Глаголы этой группы распадаются на две подгруппы. Первая из них включает в себя глаголы, которые обозначают действие, производимое его субъектом, т. н. субъектно-аттенуативный СД: побегать (немного). Вторая из них содержит глаголы, обозначающие действие, направленное на его объект или на его объекты, т. н. объектно-аттенуативный СД: приоткрыть (немного) окно.

\section{3. Формальные показатели, выражающие значение событий}

Аспектуальные значения выражаются в русском языке посредством аспектуальных маркеров (АМ), к которым относятся морфологические маркеры (ММ) (приставки, суффиксы, постфикс -ся и комбинациии этих морфем) у глаголов типа попить (см. пример (1-1)) и заплакать (см. пример (2-1)) и лексические маркеры (ЛМ), которые подразделя- 
ются на глагольные и неглагольные. К первым из них относятся служебные глаголы типа начать в конструкции начать плакать (см. пример (2-2)). Ко вторым из них относятся наречия типа немного в конструкции выпить немного молока (см. пример (1-2)).

(1-1) Нина попила (немного) / *много /* две чашки / *примерно 300 грамм молока;

(1-2) Нина выпила немного / много / две чашки / примерно 300 грамм молока;

(2-1) Мальчик обиделся и горько заплакал;

(2-2) Мальчик обиделся и начал горько плакать.

ММ, манифестирующие вторичные события, обнаруживают синкретизм видовой и акциональной информации. Так, приставка по- глагольной лексемы попить в примере (1-1) выражает совокупно видовое (= перфективное) и акциональное (= аттенуативное, или смягчительное) значения. Наречие немного дублирует в этом примере акциональную информацию, свойственную префиксу по-, и как факультативный маркер заключается в скобки. Оба эти аспектуальные значения в примере (1-2) представлены раздельно посредством разных аспектуальных маркеров (AМ): аттенуативное значение выражается посредством ЛМ немного с акциональным значением степени интенсивности действия, а индикатором перфективности служит префикс вы- глагольной лексемы bыпить. Этот префикс не имеет аттенуативного значения.

Маркированные (т. е. более сложные) глаголы с синкретическими ММ обнаруживают ограничения в сочетаемости по сравнению с глаголами, лишеными синкретических ММ. В примере (1-1)) глагол попить не сочетается с ЛМ, обозначающими большое количество, точное количество и приблизительное количество. Структуры с ЛМ являются и более весомыми по отношению к структурам с ММ. При коллизии значений структур с ММ и структур с ЛМ более „сильными” оказываются последние, которые и определяют итоговую акциональную интерпретацию всего высказывания. Так, аттенуативное значение приставки под- в примере (3-1) (подлечиться = немного полечить себя) хорошо согласуется с ЛМ слегка, указывающим на ослабленную степень проявления действия, но находится в противоречии с ЛМ основательно, обозначающим полноту осуществления действия в примере (3-2). В итоге высказывание (3-2) получает значение сатуративного, а не аттенуативного СД .

(3-1) Игорь летом ездил на курорт, хорошо отдохнул и слегка подлечился;

(3-2) Лида побывала недавно в санатории и основательно подлечилась.

Немаркированные структуры с ЛМ в некоторых контекстах могут замещать маркированные структуры с ММ. В стандартных контекстах 
приставка про- выражает пердуративное значение (см. пример (4-1) с глаголом прогулять). В таких контекстах делимитативное значение исключается. В нестандартных контекстах (см. пример (4-2) с глаголом проработать) обнаруживается интерференция пердуративного значения с делимитативным значением. В позиции нейтрализации морфологически релевантного противопоставления пердуративного СД с приставкой про- и делимитативного СД с приставкой по- дифференциация этих двух способов действия осуществляется в этом примере посредством ЛМ цзелые двадиуать лет и всего один год. Приставка пров примере (4-2) утрачивает пердуративное значение и выступает как экспонент только СВ.

(4-1) Настя прогуляла сегодня в городе целые три часа / *всего полчаса;

(4-2) Олег проработал на заводе целые двадцать лет / всего один год.

Следует указать на то, что тенденция к грамматикализации ММ прослеживается прежде всего в некодифицированных сферах русского языка, откуда она распространяется и на литературный русский язык. Так, в Большом толковом словаре русского языка 9 глагол пролечить (пролечить двести детей) со значением 'провести лечение' и с пометой профессионально-разговорного стиля речи рассматривается как омоним с глаголом пролечить с акциональным значением (пролечить больного полгода). В итоге число глагольных форм с грамматикализованными чистовидовыми приставками у глагола лечить возрастает до 6: вылечить - вылечивать, излечить - излечивать и пролечить - пролечивать.

Русский язык характеризуется высоким удельным весом ММ при манифестации СД по сравнению с неславянскими языками. Так, в немецком языке при оформлении СД также используются все три типа аспектуальных маркеров (МM, КМ и СМ), однако доля ММ здесь довольно ограниченная по сравнению с русским языком ${ }^{10}$.

\section{4. Квантитативные параметры глагола в сопоставлении с количественными характеристиками имени существительного в русском языке}

Центральной для глаголов со значением событий в зоне ЛА является нечисловая квантификация глагольного действия. Из четырех подклассов глагольных лексем со значением событий только один

${ }^{9}$ Больиой толковый словарь русского языка, ред. С. А. Кузнецов, Санкт-Петербург 2000, с. 1014.

10 В. Д. К л и м о н о в, Типологические параметры лексических видов (на материале класса событий в русском и немецком языках), [в:] Типология вида / аспекта: проблемы, почски, решения, Симферополь 2014, с. 65-66. 
из них, а именно третий, выражает числовую квантификацию глагольного действия: семельфактивы типа изарапнуть и дистрибутивы типа перецарапать (всю мебель, о кошке) обнаруживают числовую квантификацию глагольного действия по признаку "один - больше одного" на нетемпоральной шкале аспектуальности. Первый подкласс глаголов, обозначающий фазовость глагольного действия (со значениями начала и конца действия типа заговорить и договоритъ), и второй подкласс глаголов, обозначающий ограничение глагольного действия во времени (со значениями длительности и недлительности временного ограничения типа проговорить и поговорить), выражают нечисловую квантификацию глагольного действия на шкале внутренней темпоральности глагольного действия. Четвертый подкласс глаголов, обозначающий степени интенсивности глагольного действия (со значениями высокой степени интенсивности и ослабленной интенсивности действия типа набегаться и побегать), выражает нечисловую квантификацию глагольного действия типа „много - мало” на нетемпоральной шкале квантификации глагольного действия.

В сфере ГА формы СВ и НСВ в видовых парадигмах типа читать - прочитать выражают квантитативное отношение „целое - часть” на шкале внутренней темпоральности глагольного действия. Глагольные лексемы СВ типа прочитать (роман от начала до конияа) обозначают целостное действие и имеют специфицированные исходную и конечную границы действия. Глагольные лексемы НСВ типа читать (срединную главу романа) выражают нецелостное действие с неспецифицированными квантитативными координатами начала и конца действия. Соотношение „целое - часть” является градацией степени проявления глагольного действия. Глаголы СВ обозначают полноту проявления глагольного действия, тогда как глаголы НСВ указывают на неполноту осуществления действия. Мера полноты проявления глагольного действия является нечисловой квантификацией глагольного действия. Числовая квантификация, присущая только одному подклассу глаголов со значением событий в зоне ЛА, является, следовательно, маргинальной для глаголов.

Числовая квантификация у глаголов обнаруживает аналогию с числовой квантификацией у имен существительных: противопоставление как исчисляемых (нумеральных) глагольных действий (событий), так и предметов (индивидуативов) осуществляется по признаку единичности ([+ЕДИН]) и неединичности ([-ЕДИН]). Между числовой квантификацией у глаголов и у существительных обнаруживаются, однако, существенные различия. Если числовое противопоставление у существительных, выражаемое противопоставлением форм ед. ч. 
и мн. ч., имеет статус грамматикализованного противопоставления, т. е. рассматривается как числовая парадигма, то числовое противопоставление у глаголов имеет характер словообразовательной деривации, в которой производные формы обнаруживают по сравнению с исходными формами дополнительное модифицирующее значение. По этой причине числовое противопоставление у глаголов нельзя считать видовыми парадигмами. Такое противопоставление формально соотносительных глаголов является видовой корреляцией. Имена существительные обнаруживают и иную дистрибуцию числовой и нечисловой квантификации. Показательной для имен существительных является числовая квантификация. Большинство русских существительных составляют дискретные существительные, или индивидуативы. Такие существительные обнаруживают числовую квантификацию типа „один - больше одного”: стакан - стаканы. Недискретные существительные, или континуативы, с нечисловой квантификацией типа железо образуют периферию русских существительных. Квантификация со значением градации количества выражается у таких существительных посредством неграмматикализованных перифрастических экспонетов неточного количества типа много / множество / большое количество железа. Такое значение у глаголов манифестируется морфологически посредством соответствующей приставки, ср. наесться (= съесть много) и поесть (= съесть немного). У глаголов ситуация, можно сказать, обратная по отношению к именам существительным: ядро образуют здесь нечисловые пртивопоставления, тогда как числовое противопоствление является периферийным.

\section{Библиография}

Большой толковый словарь русского языка, ред. С. А. Кузнецов, Санкт-Петербург 2000.

Б о н д а р к о А. В., Содержание и типы аспектуальных отношений, [в:] Теория функициональной грамматики: Введение. Аспектуальность. Временная локализованность. Таксис, Ленинград 1987, с. 52.

К л и м о н о в В. Д., Типологические параметры лексических видов (на материале класса событий в русском и немецком языках), [в:] Типология вида / аспекта: проблемы, поиски, решения, Симферополь 2014, с. 65-66.

М а с л о в Ю. С., Об основных понятиях аспектологии, [в:] его же, Очерки по аспектологии, Ленинград 1984.

Русская Грамматика, kn. 1, Academia, Československé akademie věd, Praha 1979.

Русская грамматика, ред. Н. Ю. Шведова, т. I, Наука, Москва 1980. 
I s a č e n k o A.V., Die russische Sprache der Gegenwart, Teil I: Formenlehre, Halle (Saale) 1962.

M o u r e 1 a t o s A.P.D., Events, Processes, and States, "Syntax and Semantics" 1981, no. 14, c. $199-201$.

$\mathrm{S} \mathrm{t}$ a $\mathrm{w} \mathrm{n}$ i c k a J., Parametry kwantyfikacyjne akcji werbalnej w jezzyku polskim, [в:] B. B r e h m e r et al. (Hrsg.), Aspekte, Kategorien und Kontakte slavischer Sprachen, Festschrift für Volkmar Lehmann zum 65. Geburtstag, Hamburg 2008, c. 385. 